\title{
Sepsis knowledge, skills and attitudes among ward-based nurses
}

Edwards, Eirian; Jones, Lorelei

\section{British Journal of Nursing}

DOI:

10.12968/bjon.2021.30.15.920

Published: 12/08/2021

Peer reviewed version

Cyswllt i'r cyhoeddiad / Link to publication

Dyfyniad o'r fersiwn a gyhoeddwyd / Citation for published version (APA):

Edwards, E., \& Jones, L. (2021). Sepsis knowledge, skills and attitudes among ward-based nurses. British Journal of Nursing, 30(15), 920-927.

https://doi.org/10.12968/bjon.2021.30.15.920

\section{Hawliau Cyffredinol / General rights}

Copyright and moral rights for the publications made accessible in the public portal are retained by the authors and/or other copyright owners and it is a condition of accessing publications that users recognise and abide by the legal requirements associated with these rights.

- Users may download and print one copy of any publication from the public portal for the purpose of private study or research.

- You may not further distribute the material or use it for any profit-making activity or commercial gain

- You may freely distribute the URL identifying the publication in the public portal ?

Take down policy

If you believe that this document breaches copyright please contact us providing details, and we will remove access to the work immediately and investigate your claim. 
Title

Sepsis knowledge, skills and attitudes among ward-based nurses

\section{Abstract \\ Background}

Nurses are in a prime position to identify sepsis early by screening patients for sepsis, which should be embedded into their daily practice. However, compliance with the sepsis bundle remains low.

\section{Aims}

To explore the effects of Sepsis training on knowledge, skills and attitude among ward-based nurses.

\section{Methods}

Registered nurses from sixteen acute surgical and medical wards were invited to anonymously complete a questionnaire.

\section{Findings}

Response rate was $39 \%(98 / 250)$. Nurses with sepsis training had better knowledge with regards to NEWS score for sepsis screening, SIRS criteria, demonstrated a more positive attitude towards sepsis screening and management, were more confident in screening patients for sepsis and more likely to have screened a patient for sepsis.

\section{Conclusions}

Sepsis training improves nurses' attitude, knowledge and confidence with regards to sepsis screening and management resulting in adherence to evidence-based care and should become mandatory to all clinical staff. 


\section{Key Points}

- Sepsis when not identified early can lead to organ dysfunction and potentially death, despite this, evidence suggests that compliance with the sepsis bundle remains low

- Nurses are in a prime position to identify sepsis early by screening patients for sepsis and initiating the sepsis bundle as part of their daily routine

- This study used a questionnaire to investigate the effects of sepsis training for ward-based nurses on knowledge, skills and attitudes to sepsis screening and initiation of the sepsis bundle, also explored barriers and facilitating factors faced by ward nurses

- Nurses with sepsis training had better sepsis screening knowledge, were more confident and demonstrated a more positive attitude with regards to sepsis screening and management and were more likely to have screened a patient for sepsis

- Ward-based nurses identified tools such as the sepsis screening tool, training and peer support as facilitating factors to sepsis screening and initiation of the sepsis bundle, whereas workload, staffing levels and lack of skills such as venepuncture and cannulation were identified as barriers

- Currently, sepsis training does not form part of statutory mandatory training for front line clinical staff in every health board, therefore, the findings from this study strengthens the argument that sepsis training should become mandatory

\section{Key Words}

Sepsis; Sepsis screening; Systemic Inflammatory Response Syndrome (SIRS); NEWS; Sepsis training 


\section{Background}

Sepsis is a systemic inflammatory response syndrome (SIRS) with a suspected source of infection, which can be life threatening and lead to organ dysfunction when it is not recognised and treated early (Daniels 2010). Although the SIRS criteria is still often used in clinical practice, the use of two or more SIRS criteria to identify sepsis is no longer recommended, and has been removed from the current sepsis definition. Sepsis has recently been redefined as a "Life-threatening organ dysfunction caused by a dysregulated host response" (Singer et al, 2016). There are more than 250,000 episodes of sepsis in the United Kingdom (UK) annually resulting in approximately 44,000 deaths (Daniels and Nutbeam 2017). In the UK, improving the recognition and treatment to sepsis is a national priority and the focus of a range of national initiatives (NICE 2016; NHS England 2018).

In an effort to improve understanding, recognition and management of sepsis, a global approach has been taken with the launch of the surviving sepsis campaign (SSC) in 2002. The campaign aimed to increase health professionals' knowledge about identifying and treating sepsis through the implementation of bundles to provide a standardised approach. The sepsis bundle known as the "Sepsis Six" consists of three therapeutic and three diagnostic interventions: delivery of antibiotics, oxygen and intravenous fluid, obtaining blood cultures, measuring lactate and monitoring of urine output (Daniels and Nutbeam 2017). Mortality from sepsis can be reduced by early recognition and treatment with antibiotics. The delivery of the sepsis six bundle within one hour has shown to reduce mortality by $47 \%$ (Daniels et al. 2011).

Screening for sepsis allows for early detection of patients with potential sepsis. Nurses are in a prime position to carry out sepsis screening and initiate the sepsis six bundle as part of their daily routine (McCaffery et al. 2016; Torsvik et al. 2016). In Wales there is a standardised approach to sepsis screening known as the 'triple trigger tool' (Jones and Hancock 2017). Patients are identified as septic positive with a National Early Warning Score (NEWS2) of three or more; two or more SIRS criteria (Box 1); and suspicion of new infection (Hancock 2015; Daniels and Nutbeam 2017). 
Systemic Inflammatory Response Syndrome (SIRS) Criteria

- Temperature $>38$ or $<36^{\circ} \mathrm{C}$

- Heart rate $>90 /$ min

- Respiratory rate $>20 / \mathrm{min}$

- White cells $<4$ or $>12 \times 10^{9} / \mathrm{L}$

- $\quad$ Acutely altered mental status

- Hyperglycaemia (glucose $>7.7 \mathrm{mmol} / \mathrm{l}$ ) (in non-diabetic)

Box 1: Systemic Inflammatory Response Syndrome (SIRS) Criteria. Adapted from Daniels and Nutbeam (2017).

The SSC wants every nurse to commit to sepsis screening every patient, every shift, every day, to ensure that sepsis is not missed (SSC 2016). Early recognition and treatment of sepsis can make all the difference in preventing organ failure. A delay in screening for sepsis leads to a delay in identifying sepsis, which results in delayed treatment and management (Walters 2018). Nurses are in a prime position to identify patients who are unwell or deteriorating since nurses spend most of their time with patients. Therefore, nurses need to be educated to screen patients to identify sepsis and commence treatment to ensure compliance with the sepsis bundle within an hour.

Undertaking all the steps required to complete the sepsis six within one hour is challenging. Barriers include nurses' skills, staff shortages, distractions, poor communication and delay in the prescribing of antibiotics (Matthaeus-Kraemer et al. 2016; Tarrant et al. 2016; Roberts et al. 2017a; Roberts et al. 2017b; Breen and Rees 2018). Although a lack of training has been identified as a barrier to implementation of the sepsis bundle (Roberts et al. 2017a), few studies have evaluated the effects of sepsis training.

Most studies on the implementation of the sepsis six bundle have been undertaken in the Emergency Department. However, patients who are already in hospital are vulnerable to 
deteriorating and developing sepsis. In a multicentre study of the prevalence of patients with sepsis or severe sepsis on the general wards and Emergency Departments in Wales, Szackmany et al (2016) found that $5.5 \%$ of all in-patients outside of critical care had sepsis or severe sepsis. Compliance with the sepsis bundle was found to be low, with only $3 \%$ of septic patients and $9 \%$ of patients with severe sepsis having the bundle completed (Szackmany et al. 2016). This study investigated the outcomes of sepsis training on knowledge, skills and attitude of ward-based nurses in relation to screening and initiation of sepsis treatment, since this is a neglected area. We also explored the perceived barriers to screening patients and completing the sepsis bundle among ward nurses.

\section{Aim}

The aim of this study was to explore the effects of Sepsis training on knowledge, skills and attitude among ward-based nurses in relation to sepsis screening and the delivery of the sepsis bundle within an hour.

\section{Methods}

The study used a cross-sectional survey design. An anonymous questionnaire was developed which was based on a review of the literature. The survey contained 22 closed questions with a mixture of Yes/No, rating scale, and multiple-choice response options and two open-ended questions to capture staff views and experience. Age, length of service, band, area of work, and sepsis training status were collected (Table 1). The questionnaire was piloted with five nursing staff attending sepsis training and two nurse practitioners working within the critical care outreach team, which provided assurance that the questions were understood and provided appropriate data for analysis, which ensured the reliability and validity of the questionnaire.

The study was carried out in an acute NHS teaching hospital in Wales which serves a population of 240,000 over a large geographical area. Registered nurses from sixteen acute surgical and medical 
wards were invited to anonymously take part in the study over a four week period between February and March 2019. In total, there were 250 potential participants that fitted the inclusion criteria for this study (registered nurses working as a band five or six with a permanent or temporary contract, working on an acute medical or surgical ward). Questionnaires were returned anonymously in a sealed postal box. 
Table 1 Sepsis Questionnaire.

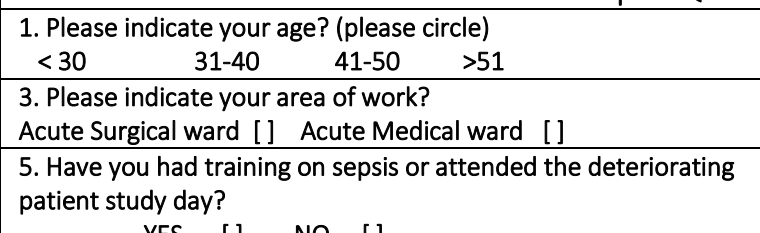
YES [ ] NO [ ]

7. Have you ever screened a patient for sepsis? YES [] NO [] NOT SURE []

2. How many years have you been a registered nurse?

4. Please indicate which Band you are working at?

Band 5 [] Band 6 []

6. At what National Early Warning Score (NEWS) should patients start to be screened for Sepsis? (please circle the correct score) $\begin{array}{lllllllll}1 & 2 & 3 & 4 & 5 & 6 & 7 & 8 & 9+\end{array}$

8. Are you familiar with the Systemic inflammatory response syndrome (SIRS) criteria? YES [] NO [] NOT SURE [ ]

9. Which of the following indicators are used when screening patients for sepsis using the SIRS criteria? Please tick all that apply

\begin{tabular}{|l|l|l|l|}
\hline Temperature $<36$ & & Temperature $>38$ \\
\hline Heart rate $>90 \mathrm{bpm}$ & & Systolic $\mathrm{BP}<90$ \\
\hline New need for Oxygen to maintain $\mathrm{SaO}_{2}>90 \%$ & & Respiratory rate $>20 /$ min & \\
\hline WCC $>12 \times 10^{9} / \mathrm{L}$ & & History or signs of a new infection & \\
\hline WCC $<4 \times 10^{9} / \mathrm{L}$ & & Lactate $\geq 4$ \\
\hline Hyperglycaemia $\mathrm{BM}>7.7$ in Non-Diabetic & & Acutely Altered Mental State & \\
\hline
\end{tabular}

10. On a scale of $1-10$ ( $1=$ no confident, $10=100 \%$ confident) How confident are you of your answer to question 9 ? (please circle)

$\begin{array}{llllllllll}1 & 2 & 3 & 4 & 5 & 6 & 7 & 8 & 9 & 10\end{array}$

\begin{tabular}{|c|c|c|c|c|c|c|c|}
\hline & \multicolumn{2}{|c|}{$\begin{array}{l}\text { 11. For Sepsis Six to be carried out certain skills are needed. Please } \\
\text { indicate which response applies to you for each skill by placing a } \\
\text { tick in the correct box: }\end{array}$} & \multicolumn{2}{|c|}{$\begin{array}{l}\text { Competent } \\
\text { in } \\
\text { performing } \\
\text { skill }\end{array}$} & \multirow[t]{2}{*}{$\begin{array}{l}\text { Received } \\
\text { training } \\
\text { but do not } \\
\text { carry out } \\
\text { skill }\end{array}$} & $\begin{array}{l}\text { Not } \\
\text { trained but } \\
\text { would like } \\
\text { to receive } \\
\text { training }\end{array}$ & $\begin{array}{l}\text { Not } \\
\text { trained } \\
\text { and not } \\
\text { interested } \\
\text { in } \\
\text { receiving } \\
\text { training }\end{array}$ \\
\hline \multirow{5}{*}{$\stackrel{n}{\stackrel{2}{*}}$} & 11a & VENEPUNCTURE & & & & & \\
\hline & $11 b$ & PERIPHERAL CANNULATION & & & & & \\
\hline & $11 \mathrm{c}$ & FEMALE CATHETERISATION & & & & & \\
\hline & $11 d$ & MALE CATHETERISATION & & & & & \\
\hline & $11 \mathrm{e}$ & IV ADMINISTRATION & & & & & \\
\hline \multicolumn{3}{|c|}{$\begin{array}{l}\text { Please indicate how much you agree or disagree with the } \\
\text { following statements by placing a tick in the appropriate box? }\end{array}$} & $\begin{array}{l}\text { Strongly } \\
\text { agree }\end{array}$ & Agr & $\begin{array}{l}\text { Neither } \\
\text { agree or } \\
\text { disagree }\end{array}$ & Disagree & $\begin{array}{l}\text { Strongly } \\
\text { disagree }\end{array}$ \\
\hline \multicolumn{3}{|c|}{ 12. There is adequate training on sepsis } & & & & & \\
\hline \multicolumn{3}{|c|}{ 13. Screening patients for sepsis is part of my role } & & & & & \\
\hline \multicolumn{3}{|c|}{ 14. I am confident in screening patients for sepsis } & & & & & \\
\hline \multicolumn{3}{|c|}{$\begin{array}{l}\text { 15. If I had a sick patient with possible sepsis I would escalate to a } \\
\text { doctor or Critical Care Outreach Team (CCOT) to perform sepsis } \\
\text { screen }\end{array}$} & & & & & \\
\hline \multicolumn{3}{|c|}{ 16. It is part of my role to decide when to initiate sepsis six bundle } & & & & & \\
\hline \multicolumn{3}{|c|}{$\begin{array}{l}\text { 17. I would only initiate sepsis six bundle following instruction from a } \\
\text { doctor or CCOT }\end{array}$} & & & & & \\
\hline \multicolumn{3}{|c|}{$\begin{array}{l}\text { 18. There is adequate staffing for me to carry out sepsis six on septic } \\
\text { patients within an hour }\end{array}$} & & & & & \\
\hline \multicolumn{3}{|c|}{$\begin{array}{l}\text { 19. I often feel I do not have enough time to carry out sepsis six on } \\
\text { septic patients within an hour }\end{array}$} & & & & & \\
\hline \multicolumn{3}{|c|}{$\begin{array}{l}\text { 20. I prioritise carrying out sepsis six on a septic patient over other } \\
\text { task and patients }\end{array}$} & & & & & \\
\hline \multicolumn{3}{|c|}{ 21. There is often a delay in prescribing when patients are septic } & & & & & \\
\hline \multicolumn{3}{|c|}{ 22. It is part of my role to complete the sepsis six compliance bundle } & & & & & \\
\hline
\end{tabular}

23. What are the biggest barriers that prevents you completing the delivery of the sepsis six within an hour of identifying sepsis?

24. What factors facilitates you to be compliant with the sepsis six within an hour of identifying sepsis? 


\section{Analysis}

Data from the questionnaires were coded and entered into Statistical Package for Social Sciences (SPSS) for analysis. Descriptive statistics were produced for demographics. The internal consistency of the attitude questionnaire was explored using Cronbach's alpha. Mann-Whitney U test was used to explore the difference between attitudes towards sepsis screening and management for nurses who had received training and those who had not. The relationship between receiving training in sepsis and screening a patient for sepsis was tested using the Chi-square test for independence. Experience of training was also explored in relation to confidence in screening and knowledge of screening criteria and procedure (NEWS and SIRS). A coding scheme was developed from the free text by inputting the data into Excel initially where themes were identified and coded.

\section{Ethical considerations}

We obtained ethical approval from the School of Health Sciences, as well as the NHS trust research and development approval process via the Integrated Research Application System (IRAS). Since this research study was being carried out at a single NHS site, local permission was granted to undertake the study at the site.

\section{RESULTS}

In total, 250 questionnaires were distributed and 98 returned, which gave a response rate of $39 \%$. Of the 98 respondents, $85 \%$ had two or more years' experience post qualification, $59(60 \%)$ worked on a medical ward and $39(40 \%)$ worked on a surgical ward. The majority of the respondents $(88 / 98$, 90\%) were working as a band 5 with only 10 (10\%) working as a band 6 . Of the 98 respondents, 72 (73\%) had received sepsis training with $26(27 \%)$ having not received any sepsis training. Sepsis training within the acute hospital where the study was undertaken is not mandatory. The Advanced Nurse Practitioners working in the Critical Care Outreach team offer a one day monthly course in the hospital on recognising and managing deteriorating patients which includes sepsis training. This 
training is available for both registered nurses and health care assistants. The sepsis training consists of SIRS criteria, recognising sepsis using the sepsis screening tool and the sepsis six bundle.

\section{NEWS sepsis screening knowledge}

Respondents were asked to indicate at what NEWS patients should be screened for sepsis on a score scale of 1 to $9+$. Of the 98 respondents, $68(69 \%)$ answered correctly and selected to start sepsis screening with a NEWS of 3 . Most respondents $(80 / 98,82 \%)$ had screened a patient for sepsis, 15 (15\%) had not screened a patient for sepsis and 3 (3\%) were not sure.

\section{SIRS knowledge}

The survey was designed to assess the respondents' knowledge on the correct SIRS criteria elements to screen patients for sepsis (Table 2). Knowledge was lowest with regards to biochemical markers. The majority (66/98) incorrectly selected that systolic BP $<90$ and new need for oxygen to maintain saturation $>90 \%$ were elements of the SIRS screening criteria, with a similar number $(60 / 98)$ incorrectly selecting lactate greater than four. These elements are an indication of organ dysfunction and hypoperfusion and not elements of the SIRS screening criteria (Daniels 2010).

Table 2: Frequency of SIRS criteria correct and incorrect answers ( $n=98)$

\begin{tabular}{|l|r|r|}
\hline \multicolumn{1}{|c|}{ SIRS Criteria (Correct) } & Selected & Not Selected \\
\hline Temperature $<36^{\circ} \mathrm{C}$ & $67(68 \%)$ & $31(32 \%)$ \\
\hline Temperature $>38^{\circ} \mathrm{C}$ & $94(96 \%)$ & $4(4 \%)$ \\
\hline Heart rate $>90 \mathrm{bpm}$ & $85(87 \%)$ & $13(13 \%)$ \\
\hline Respiratory rate $>20 / \mathrm{bpm}$ & $85(87 \%)$ & $13(13 \%)$ \\
\hline WCC $>12$ & $65(66 \%)$ & $33(34 \%)$ \\
\hline WCC $<4$ & $43(44 \%)$ & $55(56 \%)$ \\
\hline BM $>7.7$ in non-diabetic & $48(49 \%)$ & $50(51 \%)$ \\
\hline Acutely altered mental state & $73(75 \%)$ & $25(25 \%)$ \\
\hline Sign of a new infection & $71(72 \%)$ & $27(28 \%)$ \\
\hline \multicolumn{1}{|c|}{ SIRS Criteria (incorrect) } & & \\
\hline
\end{tabular}




\begin{tabular}{|l|r|r|}
\hline Systolic BP < 90mmHg & $66(67 \%)$ & $32(33 \%)$ \\
\hline $\begin{array}{l}\text { New need for oxygen to maintain } \\
\text { saturations }>90 \%\end{array}$ & $66(67 \%)$ & $32(33 \%)$ \\
\hline Lactate $>4$ & $60(61 \%)$ & $38(39 \%)$ \\
\hline
\end{tabular}

\section{Skills required to carry out sepsis six}

Patients identified as positive on the septic screen need to have the sepsis six bundle implemented within an hour. Possessing skills such as venepuncture and cannulation means that nurses are able to perform elements of the sepsis six bundle such as obtaining blood cultures, lactate and cannulation without having to rely on other members of the multidisciplinary team which improves bundle compliance within the hour. Having to wait for other members of the multidisciplinary team to undertake these tasks on ward patients leads to delay (Tarrant et al. 2016). Respondents were asked to select their competency level for the various skills required to carry out the sepsis six within an hour. Ward nurses lack skills such as venepuncture, peripheral cannulation and male catheterisation. Interestingly, $21 \%$ of the respondents identified that they had received venepuncture training but did not carry out the skill. There was a similar finding with regards to peripheral cannulation (18\%). There was a high interest in receiving training in the areas where the skills are lacking, such as venepuncture, peripheral cannulation and male catheterisation (Fig. 1).

Figure 1: Skills required to carry out sepsis six.

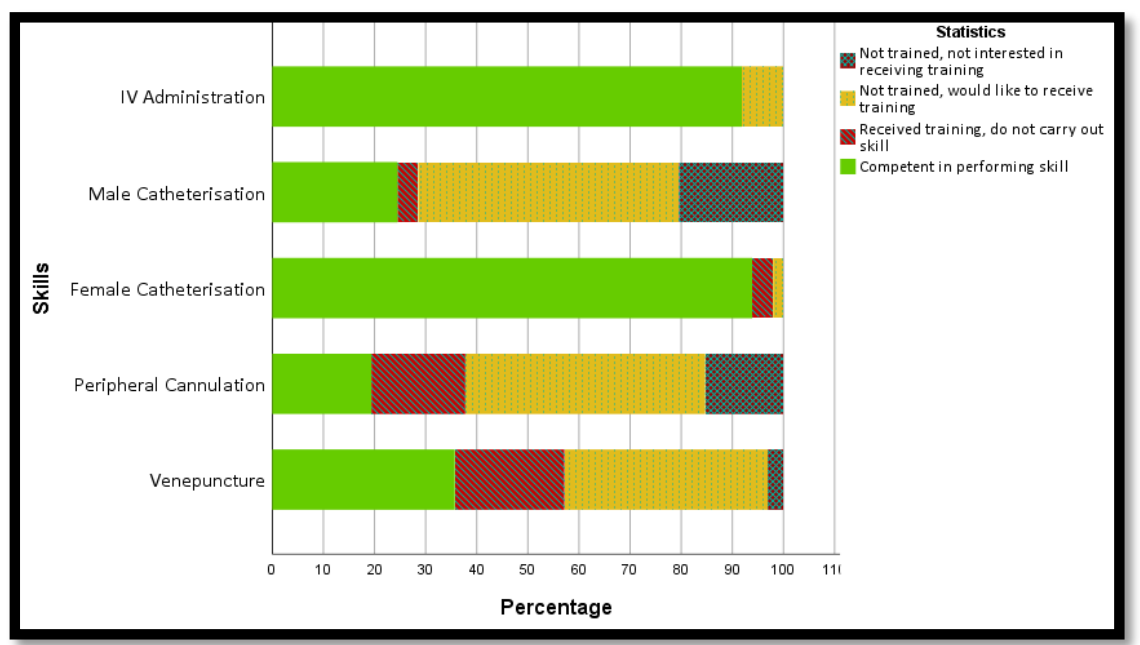




\section{Behaviour and attitude statements}

The answers to the attitude statements are given in table 3.

Table 3: Sepsis screening: attitudes of ward nurses

\begin{tabular}{|c|c|c|c|c|c|}
\hline Statements & $\begin{array}{l}\text { strongly } \\
\text { disagree } \\
\%(n)\end{array}$ & $\begin{array}{l}\text { Disagree \% } \\
\text { (n) }\end{array}$ & $\begin{array}{l}\text { neither agree or } \\
\text { disagree } \%(n)\end{array}$ & $\begin{array}{l}\text { Agree } \\
\%(n)\end{array}$ & $\begin{array}{c}\text { strongly agree } \\
\%(n)\end{array}$ \\
\hline $\begin{array}{l}\text { Q12. There is adequate training } \\
\text { on sepsis }\end{array}$ & $\begin{array}{l}1 \% \\
(1)\end{array}$ & $\begin{array}{l}12 \% \\
(12)\end{array}$ & $\begin{array}{l}15 \% \\
(15)\end{array}$ & $\begin{array}{l}59 \% \\
(58)\end{array}$ & $\begin{array}{l}12 \% \\
(12)\end{array}$ \\
\hline $\begin{array}{l}\text { Q13.Screening patients for } \\
\text { sepsis is part of my role }\end{array}$ & (0) & (0) & $\begin{array}{l}2 \% \\
(2)\end{array}$ & $\begin{array}{l}38 \% \\
(37)\end{array}$ & $\begin{array}{l}60 \% \\
(59)\end{array}$ \\
\hline $\begin{array}{l}\text { Q14. I am confident in } \\
\text { screening patients for sepsis }\end{array}$ & (0) & $\begin{array}{l}8 \% \\
(8)\end{array}$ & $\begin{array}{l}11 \% \\
(11)\end{array}$ & $\begin{array}{l}52 \% \\
(51)\end{array}$ & $\begin{array}{l}29 \% \\
(28)\end{array}$ \\
\hline $\begin{array}{l}\text { Q15. If I had a sick patient I } \\
\text { would escalate to a doctor or } \\
\text { Critical Care Outreach Team } \\
\text { (CCOT) to perform sepsis } \\
\text { screen }\end{array}$ & (0) & $\begin{array}{l}5 \% \\
(5)\end{array}$ & $\begin{array}{l}3 \% \\
(3)\end{array}$ & $\begin{array}{l}27 \% \\
(26)\end{array}$ & $\begin{array}{l}65 \% \\
(64)\end{array}$ \\
\hline $\begin{array}{l}\text { Q16. It is part of my role to } \\
\text { decide when to initiate the } \\
\text { sepsis six bundle }\end{array}$ & (0) & $\begin{array}{l}1 \% \\
(1)\end{array}$ & $\begin{array}{l}12 \% \\
(12)\end{array}$ & $\begin{array}{l}35 \% \\
(34)\end{array}$ & $\begin{array}{l}52 \% \\
(51)\end{array}$ \\
\hline $\begin{array}{l}\text { Q17. I would only initiate the } \\
\text { sepsis six bundle following } \\
\text { instruction from a doctor or } \\
\text { CCOT }\end{array}$ & $\begin{array}{l}14 \% \\
(14)\end{array}$ & $\begin{array}{l}48 \% \\
(47)\end{array}$ & $\begin{array}{l}15 \% \\
(15)\end{array}$ & $\begin{array}{l}17 \% \\
(17)\end{array}$ & $\begin{array}{l}5 \% \\
(5)\end{array}$ \\
\hline $\begin{array}{l}\text { Q18. There is adequate staffing } \\
\text { for me to carry out sepsis six on } \\
\text { septic patients within } 1 \text { hour }\end{array}$ & $\begin{array}{l}8 \% \\
(8)\end{array}$ & $\begin{array}{l}27 \% \\
(26)\end{array}$ & $\begin{array}{l}26 \% \\
(25)\end{array}$ & $\begin{array}{l}32 \% \\
(31)\end{array}$ & $\begin{array}{l}8 \% \\
(8)\end{array}$ \\
\hline $\begin{array}{l}\text { Q19. I often feel I do not have } \\
\text { enough time to perform sepsis } \\
\text { six within an hour }\end{array}$ & $\begin{array}{l}3 \% \\
(3)\end{array}$ & $\begin{array}{l}30 \% \\
(29)\end{array}$ & $\begin{array}{l}22 \% \\
(22)\end{array}$ & $\begin{array}{l}37 \% \\
(36)\end{array}$ & $\begin{array}{l}8 \% \\
(8)\end{array}$ \\
\hline $\begin{array}{l}\text { Q20. I prioritise carrying out } \\
\text { sepsis six on a septic patient } \\
\text { over other tasks }\end{array}$ & (0) & (0) & $\begin{array}{l}10 \% \\
(10)\end{array}$ & $\begin{array}{l}46 \% \\
(45)\end{array}$ & $\begin{array}{l}44 \% \\
(43)\end{array}$ \\
\hline $\begin{array}{l}\text { Q21. There is often a delay in } \\
\text { prescribing when patients are } \\
\text { septic }\end{array}$ & (0) & $\begin{array}{l}18 \% \\
(18)\end{array}$ & $\begin{array}{l}30 \% \\
(29)\end{array}$ & $\begin{array}{l}42 \% \\
\text { (41) }\end{array}$ & $\begin{array}{l}10 \% \\
(10)\end{array}$ \\
\hline $\begin{array}{l}\text { Q22. It is part of my role to } \\
\text { complete the sepsis six } \\
\text { compliance bundle }\end{array}$ & (0) & $\begin{array}{l}1 \% \\
(1)\end{array}$ & $\begin{array}{l}4 \% \\
(4)\end{array}$ & $\begin{array}{l}52 \% \\
(51)\end{array}$ & $\begin{array}{l}43 \% \\
(42)\end{array}$ \\
\hline
\end{tabular}

The total attitude score was computed by adding the scores from the attitude statements number

$13,14,16,17,20$ and 22 . The higher score indicates a positive attitude, whereas the lower score

indicates a negative attitude. The range of the attitude score was from 18 to 30 with a mean of 25

$(S D=2.97)$, median of 25 , and a mode of 28 . The histogram (Fig. 2 ) show that the total attitude 
scores are reasonably normally distributed. The Cronbach $\alpha$ for the attitude scale was .713 which is acceptable.

Figure 2: Histogram showing the distribution of Total attitude scores.

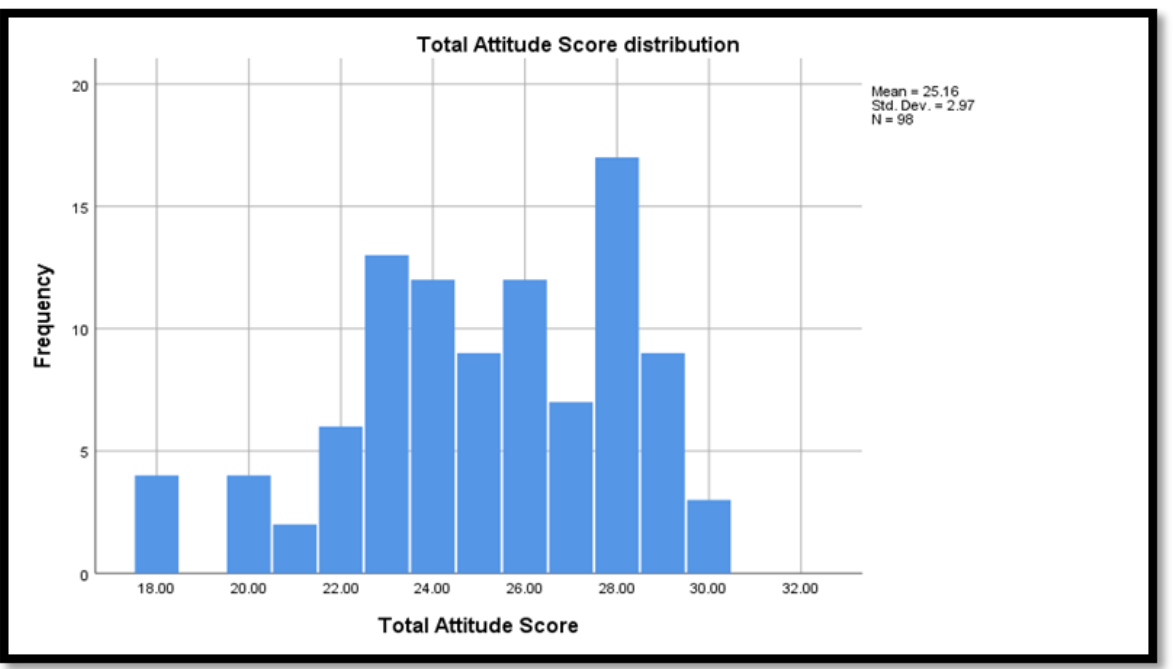

One of the primary objectives was to explore ward-based nurses' attitudes towards the implementation of the sepsis six bundle. There was a significant difference in attitude between nurses who had received sepsis training $(M=25.74, S D=2.54)$ and nurses who had not $(M=23.58$, $S D=3.51)(U=611.5, p=.009)$ in the context of the relatively small sample (Fig. 3). There were no significant differences according to specialty, age or length of service.

Figure 3: Boxplot of comparison of total attitude score between categories of sepsis training.

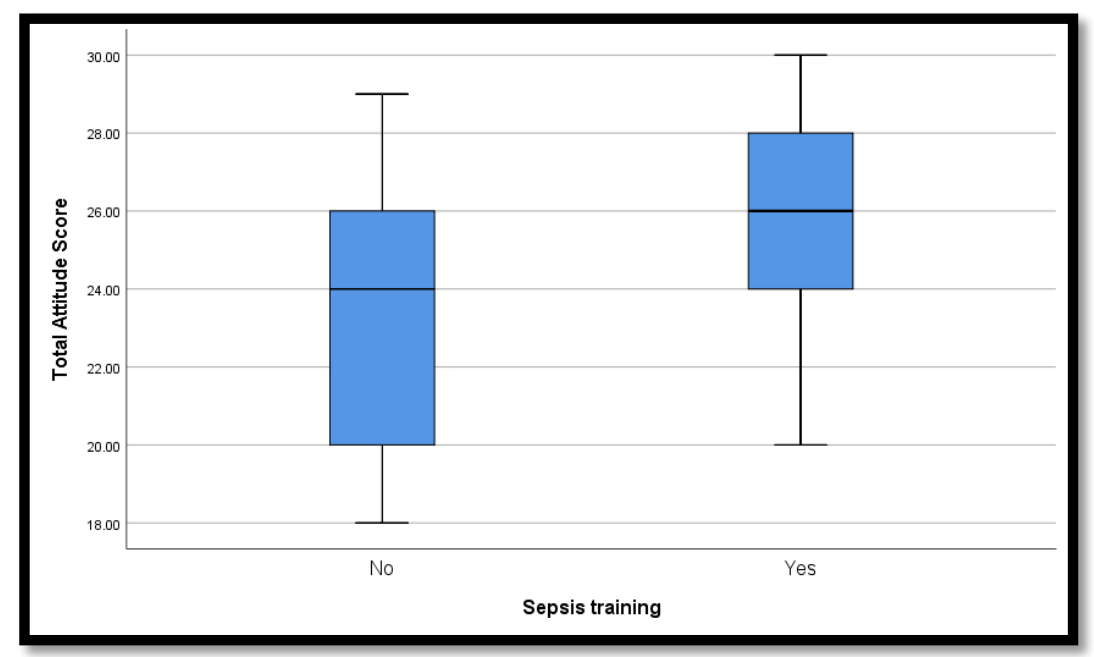




\section{Sepsis training}

Nurses who had attended sepsis training were more likely to have screened a patient for $\operatorname{sepsis} \chi^{2}(2$, $n=98)=12.17, p=.002$. From the nurses who had received training, $90 \%(65 / 72)$ have screened patients for sepsis compared to $58 \%(15 / 26)$ in the non-trained group. Nurses who had attended training on sepsis were more confident in screening patients for sepsis $\chi^{2}(3, n=98)=24.90, p<$ .001. Nurses who have attended sepsis training have better knowledge on the correct NEWS score to start screening for sepsis $\chi^{2}(1, n=98)=15.94, p<.001$. From the nurses who have received sepsis training, $81 \%(58 / 72)$ knew the correct NEWS to start sepsis screening compared to only $38 \%(10 / 26)$ in the non-trained group. Nurses who have attended sepsis training demonstrated a higher knowledge with regards to SIRS criteria $(M=53.24, S D=24.52)$ compared to nurses who had not received training $(M=40.17, S D=23.32),(U=649, p=.019)$.

\section{Barriers and facilitating factors to implementing the sepsis six bundle within 1 hour}

Respondents were asked to identify barriers that prevented them from completing the delivery of the sepsis six within an hour and factors which assist them. In total, 80 of the respondents left comments with regards to perceived barriers and facilitators, with many identifying more than one, and some leaving a lengthy response. Some of the comments are given in table 4 as an example. Themes were identified and coded and frequency analysis was carried out for barriers (Fig. 4) and facilitating factors (Fig. 5).

The top two barriers were workload and staffing levels, followed by skills, availability of doctors, and prescribing. Heavy workload and low staffing levels on the wards made it difficult to complete sepsis six within an hour. Some comments were made with regards to having unfamiliar staff working on the wards (illustrated in table 4), such as agency staff and health care assistants which could be a barrier at times when abnormal observations were not escalated appropriately. The lack of skills such as venepuncture and cannulation were also identified by many as causing a delay. Waiting for 
patients to be reviewed by a doctor, especially out of hours, was recognised as a barrier. This also resulted in prescribing delays.

The top three facilitating factors were tools, training, and support. Several respondents said that tools such as the sepsis screening tool, sepsis bundle and having a Patient Group Directive (PGD) for first dose antibiotics aided them in the delivery of the sepsis six within an hour. Training to improve knowledge was also important. It was apparent from the comments that having peer support from colleagues on the ward was essential to implementing sepsis six within an hour.

Figure 4: Staff views on barriers to implementing sepsis six bundle within one hour

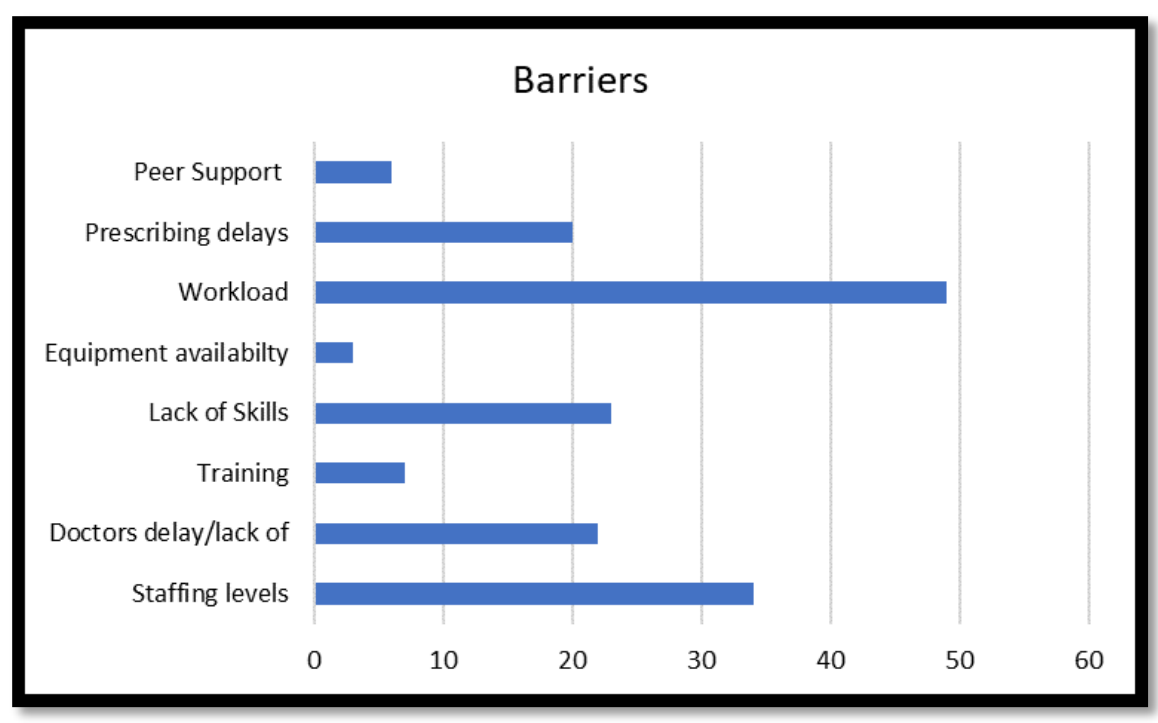

Figure 5: Staff views on factors that facilitate implementation of sepsis six bundle in one hour

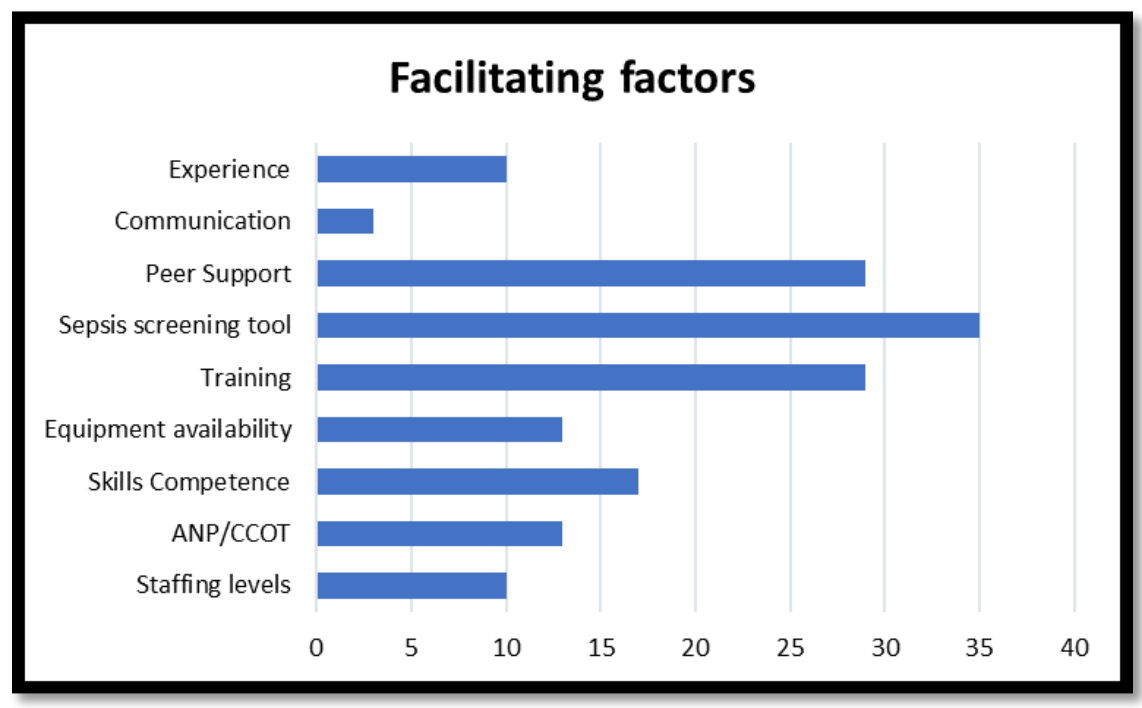


Table 4. Barriers and facilitators for implementation of the sepsis 6 bundle in one hour: perceptions of ward nurses (illustrative data from open ended questions)

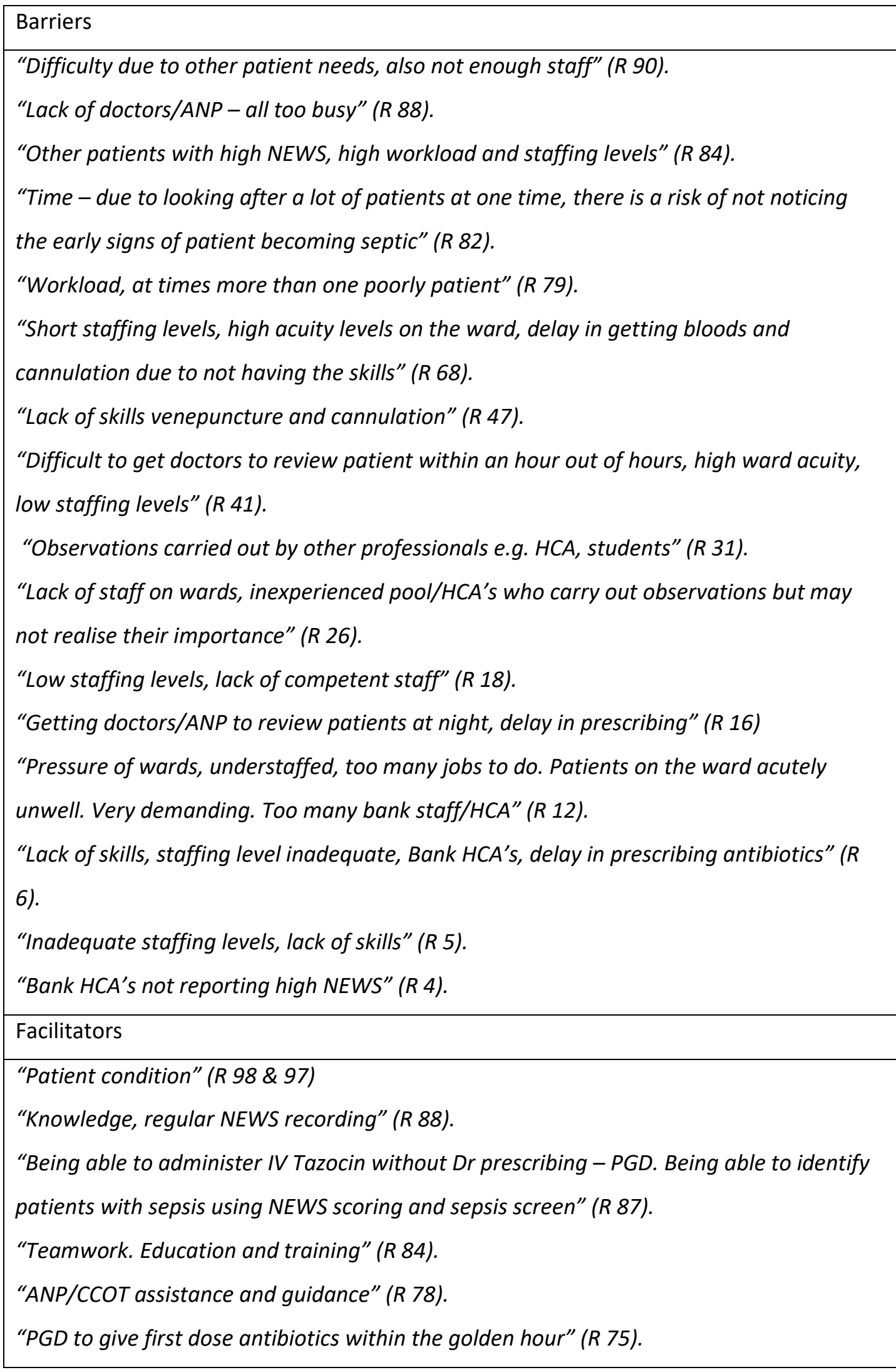


"The ANP's are so helpful and usually attend promptly, they are a valuable part of the team and assist in possible diagnosis and prompt treatment" (R 64).

"Able to call CCOT/ANP to help on the ward" (R 59).

“Clinical judgment, experience" ( $R$ 45).

"Having the sepsis screening tool at the bottom of the TPR chart to help identify sepsis" (R 40).

"My duty of care, my roles and responsibilities to the patient" ( $R 30)$.

"Training and awareness" ( $R$ 20).

"Training" (R 13).

"NEWS scoring system/trigger tool. Support from CCOT/ANP" (R 6).

"Patient stories of their experience with sepsis, study day" (R 4).

"Good team support" (R 3).

\section{DISCUSSION}

Nurses who had received sepsis training had a higher level of knowledge on NEWS screening and SIRS criteria. Nurses who had received sepsis training were more likely to have a positive attitude towards early recognition and initial management of sepsis and were more confident in carrying out sepsis screening, and are therefore more likely to screen patients which results in early identification and management. Early recognition and management of sepsis with the delivery of sepsis six within the hour is important to prevent patients deteriorating on the wards (Daniels et al. 2011; Dellinger et al. 2013; McCaffery et al. 2016). This study adds to the evidence on education and training interventions, a neglected topic in healthcare improvement research (Dixon-Woods 2019).

Not having the appropriate skills to carry out sepsis six within an hour was identified as a key barrier by respondents. To be able to carry out sepsis six within an hour, certain practical skills are required, such as venepuncture and peripheral cannulation skills as a priority. However, we found that a majority of ward nurses lack these skills. Even among those who had received training in these skills, many did not use them. Another study by Breen and Rees (2018) found that ward nurses were significantly more likely to lack these skills compared to ED nurses. A lack of the necessary skills, or a 
reluctance to use them, places patients at risk of deteriorating if there is a delay in obtaining intravenous access to administer appropriate antibiotics and fluids.

Providing nurses with training in venepuncture and cannulation will be beneficial, however, there remains the need to wait for a doctor or a nurse practitioner to prescribe the necessary treatment. Delay in prescribing, and waiting for patients to be reviewed by doctors, were identified by the respondents as a barrier to implementing the sepsis six within an hour. This supports the finding by Matthaeus-Kraemer et al (2016) that poor access to doctors on general wards is a barrier to the treatment of sepsis. For every hour delay in the administration of antibiotics there is a $7.6 \%$ increase in mortality (Kumar et al. 2006; Barochia et al. 2010; Castellanos-Ortega et al. 2010; Kumar et al. 2015). Having a Patient Group Directive (PGD) to enable nurses to administer the first dose antibiotics was identified to facilitate the implementation of the sepsis six bundle in one hour. Having a nurse-initiated sepsis protocol has been found to significantly reduce the median time to initial antibiotics (Bruce et al. 2015). Mattison et al (2016) found that having a PGD can result in timely antibiotic administration, with $96 \%$ receiving antibiotics within one hour. Having a PGD protocol overcomes some of the barriers associated with the delay in the administration of antibiotics within one hour.

Workload and staffing levels were the most frequently mentioned barrier to implementing the sepsis six bundle in one hour. Similar findings have been reported elsewhere (Burney et al. 2012; Tarrant et al. 2016; Roberts et al. 2017a; Roberts et al. 2017b; Breen and Rees 2018). However, it was not simply having adequate numbers of staff on the ward, respondents also valued support from colleagues, and good teamwork was important to implementing the sepsis six bundle. Respondents reported problems with inexperienced and unfamiliar staff (for example temporary agency staff), who carry out observations on patients but may not recognise or know when to report abnormal observations. Not reporting high NEWS and deteriorating observations to the nurse delays the identification of a potential septic patient, which put patients at risk of deteriorating. This 
supports the finding by Breen and Rees (2018) who identified that one of the biggest barriers to identifying sepsis was the lack of sepsis recognition during observation rounds. The 'hollowing out' of the NHS workforce through an overreliance on unregistered and temporary nursing staff is currently an important public policy concern (Buchan et al. 2019). This study contributes to the evidence for the effects for patient care. It also raises questions about the education and training needs of agency staff, and whether or not they have access and support to attend the same training as staff employed by the trusts.

Tools were the most frequently mentioned factor that nurses found helped them in achieving sepsis six within an hour. In this organisational setting these tools consisted of the sepsis screening tool and bundle and the screening tool on the observation chart along with the NEWS. This tool provides a nurse-initiated approach to sepsis, which empowers nurses. Previous research, mainly in emergency departments, has found that providing nurses with training and education, paired with appropriate tools can improve sepsis care (Tromp et al. 2010; Bruce et al. 2015; Drahnak et al. 2016; McCaffery et al. 2016; Torsvik at al. 2016; Shah et al. 2018).

\section{Limitations}

The overall response rate for this study was $39 \%$. Although this may seem low, it corresponds with similar studies (Roberts et al. 2017a; Breen and Rees 2018). Since the respondents self-selected into the study, this may have produced non-respondent bias. Staff who have an interest in sepsis may have been more inclined to take part in the survey compared to staff with less interest.

\section{Conclusion}

Sepsis training improves nurses' attitude, knowledge and confidence with regards to sepsis screening and initiating the sepsis bundle within an hour. Therefore, the recommendation from this study is that sepsis training should become mandatory among clinical staff. The widespread use of unregistered and temporary staff on acute wards reduces the support available for ward staff to 
screen for sepsis, and on teamwork and peer support for decision-making and use of clinical skills. Although the lack of practical skills was identified as a barrier, despite having received training on skills such as venepuncture and cannulation, majority of nurses did not use these skills, which has identified an area that requires further research to explore the underlying causes. Consideration should also be given to the impact that temporary nurse staffing has on the availability of knowledge and skills for sepsis screening.

Figures

Figure 1. Skills required for sepsis six compliance

Figure 2. Histogram showing the distribution of Total attitude score

Figure 3. Boxplot of comparison of total attitude score between categories of sepsis training.

Figure 4. Staff views on barriers to implementing sepsis six within one hour: Frequency

Figure 5. Staff views on factors that facilitate implementation of sepsis six bundle in one hour: Frequency

Tables

Table 1. Sepsis questionnaire

Table 2. Frequency of SIRS criteria correct and incorrect answers $(n=98)$

Table 3. Sepsis screening: attitudes of ward nurses

Table 4. Barriers and facilitators for implementation of the sepsis 6 bundle in one hour: perceptions of ward nurses (illustrative data from open ended questions)

\section{Reflective Questions}

- What improvement could be implemented in your clinical area to overcome some of the barriers to sepsis screening and bundle compliance?

- Think about how to improve staff knowledge on sepsis screening in your clinical area, and how this could be embedded into their daily routine as a norm 
- How can you ensure that staff in your clinical area have the necessary skills required to deliver the sepsis bundle within the hour?

\section{References}

Barochia AV, Cui X, Vitberg D, et al. 2010. Bundled care for septic shock: an analysis of clinical trials. Crit Care Med. 38(2):668-678.

Breen S, Rees S. 2018. Barriers to implementing the sepsis six guidelines in an acute hospital setting. Br J Nurs. 27(9):473-478. doi:10.12968/bjon.2018.27.9.473

Bruce HR, Maiden J, Fedullo PF, et al. 2015. Impact of nurse-initiated ED sepsis protocol on compliance with sepsis bundles, time to initial antibiotic administration, and in-hospital mortality. J Emerg Nurs. 41(2):130-137. doi:10.1016/j.jen.2014.12.007

Buchan J, Gershlick B, Charlesworth A, et al. 2019. Falling short: the NHS workforce challenge. London:The Health Foundation. https://www.health.org.uk/sites/default/files/upload/publications/2019/S05 Falling\%20short The\%20NHS\%20workforce\%20challenge.pdf (Accessed February, 2020)

Burney M, Underwood J, McEvoy S, et al. 2012. Early detection and treatment of severe sepsis in the emergency department: Identifying barriers to implementation of a protocol-based approach. $J$ Emerg Nurs. 38(6):512-517. doi:10.1016/j.jen.2011.08.011

Castellanos-Ortega A, Suberviola B, García-Astudillo LA, et al. 2010. Impact of the surviving sepsis campaign protocols on hospital length of stay and mortality in septic shock patients: results of a three-year follow-up quasi-experimental study. Crit Care Med. Apr;38(4):1036-1043. doi: 10.1097/CCM.0b013e3181d455b6 
Daniels R. 2010. Defining the spectrum of disease. In: Daniels R, Nutbeam T, eds. ABC of Sepsis. Chichester:John Wiley p.5-9.

Daniels R, Nutbeam T, McNamara G, et al. 2011. The sepsis six and the severe sepsis resuscitation bundle: A prospective observational cohort study. Emerg Med J. 28(6):507. doi:10.1136/emj.2010.095067

Daniels R, Nutbeam T. 2017. The sepsis manual, UK sepsis trust. 4th ed. https://sepsistrust.org/wpcontent/uploads/2018/06/Sepsis Manual 2017 web download.pdf (Accessed February, 2020)

Dellinger RP, Levy MM, Rhodes A, et al. 2013. Surviving Sepsis Campaign: international guidelines for management of severe sepsis and septic shock, 2012. Intensive Care Med. 39(2):165-228. doi: $10.1007 / \mathrm{s} 00134-012-2769-8$

Dixon-Woods M. 2019. How to improve healthcare improvement-an essay by Mary Dixon-Woods. BMJ. 367:I5514. doi: 10.1136/bmj.I5514

Drahnak DM, Hravnak M, Ren D, et al. 2016. Scripting nurse communication to improve sepsis care. MEDSURG Nursing. 25(4):233-239.

Hancock C. 2015. A national quality improvement initiative for reducing harm and death from sepsis in Wales. Intensive Crit Care Nurs. 31(2):100-5. doi: 10.1016/j.iccn.2014.11.004

Jones R, Hancock C. 2017. RRAILS Letter.

http://www.1000livesplus.wales.nhs.uk/sitesplus/documents/1011/RRAILS\%20Letter\%202017 \%20Adults\%20With\%20Sepsis1.pdf (Accessed February 2020)

Kumar A, Roberts D, Wood KE, et al. 2006. Duration of hypotension before initiation of effective antimicrobial therapy is the critical determinant of survival in human septic shock. Crit Care Med. 34(6):1589-1596. 
Kumar P, Jordan M, Caesar J, et al. 2015. Improving the management of sepsis in a district general hospital by implementing the 'sepsis six' recommendations. BMJ Qual Improv Rep. 4(1). doi:10.1136/bmjquality.u207871.w4032

Matthaeus-Kraemer C, Thomas-Rueddel D, Schwarzkopf D, et al. 2016. Crossing the handover chasm: Clinicians' perceptions of barriers to the early detection and timely management of severe sepsis and septic shock. J Crit Care. 36:85-91. doi:10.1016/j.jcrc.2016.06.034

Mattison G, Bilney M, Haji-Michael P, et al. 2016. A nurse-led protocol improves the time to first dose intravenous antibiotics in septic patients post chemotherapy. Support Care Cancer. 24(12):5001-5005. doi:10.1007/s00520-016-3362-4

McCaffery M, Onikoyi O, Rodrigopulle D, et al. 2016. Sepsis-review of screening for sepsis by nursing, nurse driven sepsis protocols and development of sepsis hospital policy/protocols. Nurs Palliat Care. 1(2):33-37. doi: 10.15761/NPC.1000109

National Institute for Health and Care Excellence. 2016. Sepsis: recognition, diagnosis and early management. London: National Institute for Health and Care Excellence.

NHS England. 2018. Commissioning for Quality and Innovation (CQUIN) Guidance for 2017-2019.

\section{https://www.england.nhs.uk/wp-content/uploads/2018/04/cquin-guidance-2018-19.pdf} (Accessed February, 2020)

Roberts N, Hooper G, Lorencatto F, et al. 2017a. Barriers and facilitators towards implementing the sepsis six care bundle (BLISS-1): A mixed methods investigation using the theoretical domains framework. Scand J Trauma Resusc Emerg Med. 25(1):96. doi:10.1186/s13049-017-0437-2

Roberts RJ, Alhammad AM, Crossley L, et al. 2017b. A survey of critical care nurses' practices and perceptions surrounding early intravenous antibiotic initiation during septic shock. Intensive Crit Care Nurs. 41:90-97. doi:10.1016/j.iccn.2017.02.002 
Shah T, Sterk E, Rech MA. 2018. Emergency department sepsis screening tool decreases time to antibiotics in patients with sepsis. Am J Emerg Med. 36(10):1745-1748. doi: 10.1016/j.ajem.2018.01.060

Singer M, Deutschman CS, Seymour CW, et al. 2016. The third international consensus definitions for sepsis and septic shock (sepsis-3). JAMA: Journal of the American Medical Association, 315(8):801-810 doi:10.1001/jama.2016.0287

Surviving Sepsis Campaign (SSC). 2016. Surviving Sepsis Campaign Responds to Sepsis-3. http://www.survivingsepsis.org/SiteCollectionDocuments/SSC-Statements-Sepsis-Definitions-32016.pdf (Accessed February, 2020)

Szakmany T, Lundin R, Sharif B, et al. 2016. Sepsis prevalence and outcome on the general wards and emergency departments in wales: Results of a multi-centre, observational, point prevalence study. PLoS One. 11(12):e0167230. doi:10.1371/journal.pone.0167230

Tarrant C, O'Donnell B, Martin G, et al. 2016. A complex endeavour: An ethnographic study of the implementation of the sepsis six clinical care bundle. Implement Sci. 11(1):149.

Torsvik M, Gustad LT, Mehl A, et al. 2016. Early identification of sepsis in hospital inpatients by ward nurses increases 30-day survival. Crit Care. 20(1):244. doi:10.1186/s13054-016-1423-1

Tromp M, Hulscher M, Bleeker-Rovers CP, et al. 2010. The role of nurses in the recognition and treatment of patients with sepsis in the emergency department: A prospective before-and-after intervention study. Int J Nurs Stud. 47(12):1464-1473. doi:10.1016/j.ijnurstu.2010.04.007

Walters, E. 2018. Raising awareness for sepsis, sepsis screening, early recognition, and treatment in the emergency department. Journal of Emergency Nursing; Journal of Emergency Nursing, 44(3), 224-227 doi:10.1016/j.jen.2017.10.008 